\title{
A new genus and species of Tortricinae (Lepidoptera: Tortricidae) from China
}

\author{
Xinpu Wang \& Houhun Li*
}

Wang, X. \& Li, H. 2005: A new genus and species of Tortricinae (Lepidoptera: Tortricidae) from China. — Entomol. Fennica 16: 263-265.

A new tortricid genus Platyhomonopsis is proposed. The type species, $P$. dentata sp. nov., is described based on specimens collected in Guizhou Province. Illustrations of the adult, head, wing venation and male genitalia are provided.

Xin Pu Wang and Houhun Li*, Department of Biology, Nankai University, Weijin Road 94, Tianjin, 300071, China; correspondent author's e-mail: lihouhun @nankai.edu.cn

Received 3 July 2004, accepted 28 January 2005

\section{Introduction}

The genus Platyhomonopsis gen. $\mathrm{n}$. belongs to Archipini, Tortricinae. It is very closely related to Homonopsis Kuznetsov. The type species, Platyhomonopsis dentata sp. nov., is described from Guizhou Province, China. The type specimens are deposited in the Department of Biology, Nankai University, Tianjin, China. The terminology in this paper mostly follows Horak (1984).

\section{New taxa}

\subsection{The genus Platyhomonopsis gen. n.}

Type species: Platyhomonopsis dentata sp. $\mathrm{n}$.

Description. Ocellus posterior. Chaetosema developed. Labial palpus ascending, exceeding vertex. Forewing broad, termen moderately concave between $R_{5}$ and $M_{3}$, tornus broadly rounded.

Venation. Discocellular degenerate in forewing, veins $\mathrm{M}_{3}$ and $\mathrm{CuA}_{1}$ stalked in both forewing and hindwing.

Male genitalia. Tegumen broad and short. Uncus broad, with dense, long hairs, concave terminally, bilobed, distal portion with a few short thorns. Gnathos absent. Valva broad, with a patch of large dense thorns in middle portion. Transtilla broad. Sacculus with free termination. Juxta large. Aedeagus with small coecum penis, caulis absent.

Diagnosis. The new genus is similar to $\mathrm{Ho}-$ monopsis Kuznetsov in the presence of a broad, bilobed uncus and a patch of large dense thorns in the valva. It can be distinguished from the latter by the following characters: labial palpus exceeding vertex; veins $\mathrm{M}_{3}$ and $\mathrm{CuA}_{1}$ stalked in both forewing and hindwing; discocellular degenerate in forewing; tegumen very short and broad; uncus provided with long hairs and the distal portion with a few short thorns; gnathos absent; valva with a patch of large dense thorns in middle portion.

Distribution. China (Guizhou Province).

Etymology. The generic name is derived from the Greek prefix platy = broad, and the generic name Homonopsis, referring to the similarity of the new genus with Homonopsis.

Remarks. Costal 1/4 of the male hindwing in the new genus is provided with a large cluster of dark hairs and broad scales, which might be a specialized scent organ. Forewing has some large scales on the underside of costal base, which 

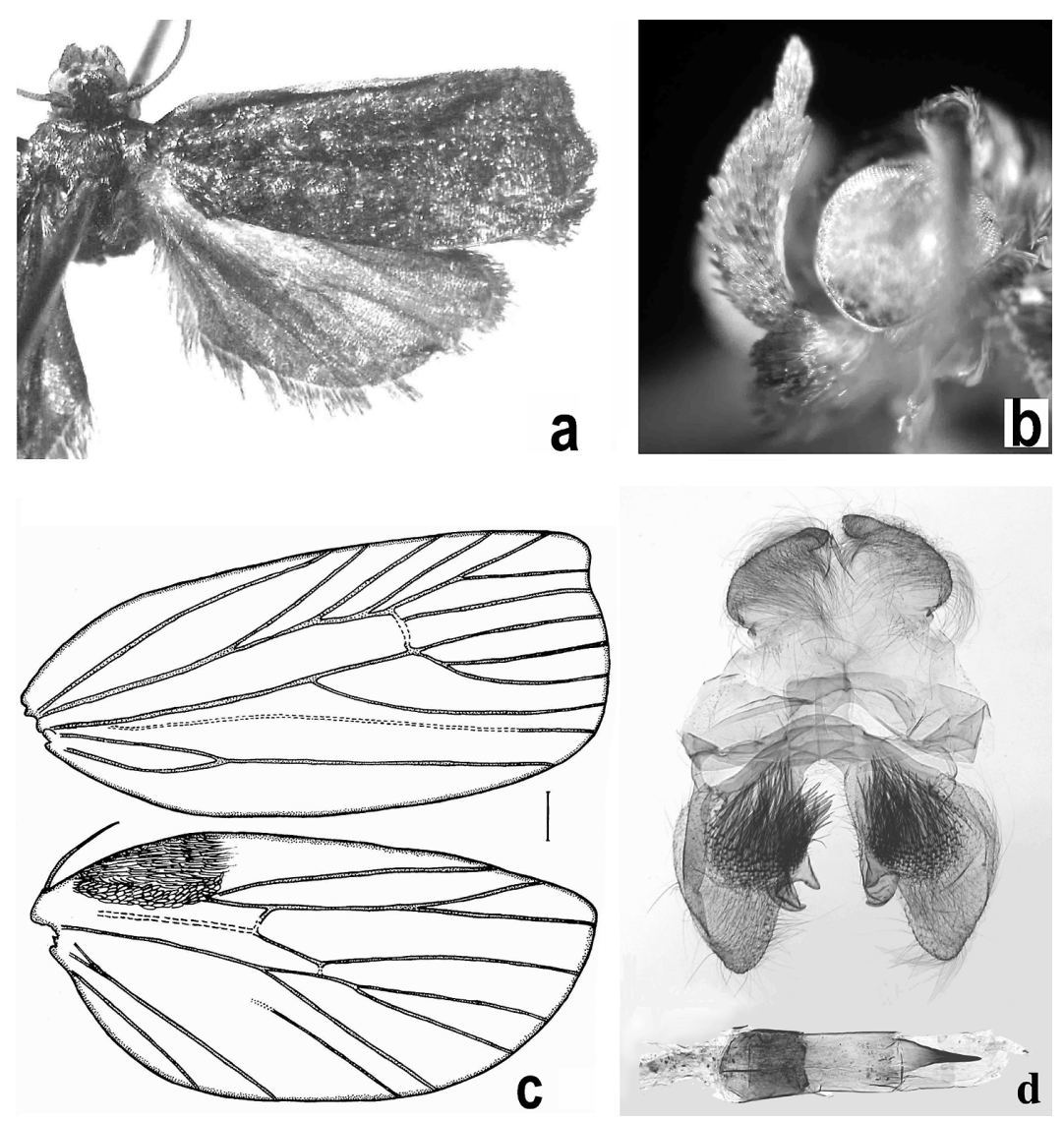

Fig. 1. Platyhomonopsis dentata sp. $\mathrm{n}$., holotype. a. Adult. b. Head. c. Venation. d. Male genitalia. Scale bar $0.5 \mathrm{~mm}$.

might be an ancillary structure of the scent organ in the hindwing. But the species of Homonopsis do not have this organ in the hindwing. It is particular that veins $\mathrm{M}_{3}$ and $\mathrm{CuA}_{1}$ are stalked in both forewing and hindwing of the new genus. However, they are not stalked in Homonopsis, but connate from angle.

The genus Homonopsis was well studied (Obraztsov, 1967, Yasuda, 1972, 1975, Kawabe 1982, Razowski 1987, Kuznetsov 2001, Liu \& Li, 2002). Both Platyhomonopsis gen. n. and Homonopsis possess very broad and bilobed uncus, which might be synapomorphy of the two genera. Bifurcate uncus occurs in several genera of Archipini, such as Chiraps, Diplocalyptis and Aphelia, but it is always slender, which may have undergone various evolutionary events.

Gnathos is absent or atrophied in Tortricini and Cochylini of Tortricinae, but it is ubiquitous in Archipini and shows variation, for example lateral process present. So gnathos might be valu- able in the classification of Tortricinae. Absent gnathos of Platyhomonopsis gen. n. could be autapomorphy.

Large thorns in the valva are rare in Archipini, but common in Olethreutinae. The thorns could be synapomorphy of Platyhomonopsis gen. n. and Homonopsis Kuznetsov, but different location of thorns might be a result of diverse evolution.

\subsection{Platyhomonopsis dentata sp. n.}

(Fig. 1a-d)

Type material. Holotype $\widehat{\jmath}$ : China, Jiangkou County (33.43 N, 107.03 E), Guizhou Province, alt. $550 \mathrm{~m}$ a.s.1., 2.VI.2002, leg. Xinpu Wang, genitalia slide No. WXP02463. Paratype: 1 , same data as holotype.

Diagnosis. The new species resembles Homonopsis illotana (Kennel) by having small 
metallic spots in the forewing, but differs from the latter in the following characters: (1) ground color of forewing dark brown; (2) uncus provided with dense and long hairs, distal portion with a few short thorns; (3) gnathos absent; (4) ventral margin of valva distally with a large dent; (5) juxta inverted pentagonal-like; (6) aedeagus pointed apically.

Description. Male (Fig. 1a-b): Wing span $17.0-18.5 \mathrm{~mm}$. Frons with short pale yellowish scales. Vertex provided with procumbent black scales. Labial palpus 1.5 times longer than diameter of compound eye; first segment short, with black scales in distal part; second segment slender and long, gradually dilated; third segment thin and short, yellowish brown. Antenna thick, with dense cilia on ventral surface. Thorax dark brown. Forewing broad, costa provided with an upward fold and some large scales on the underside of base; apex rounded; termen convex, sinuate beyond apex; ground color dark brown, with small blue metallic spots; basal part of costa dark gray; cilia black. Hindwing and cilia dark gray, costa with a large cluster of dark hairs in basal $1 / 4$, posterior margin surrounded with a band of broad yellow scales at base. Tibia and tarsus of foreleg, midleg and outer spur of hindleg dark brown. Abdomen with dorsal and lateral surface pale brown, ventral surface whitish.

Venation (Fig. 1c): Forewing with Sc gently sinuate, almost straight; $\mathrm{R}_{1}$ from behind middle of discal cell; base of $R_{2}$ slightly or twice closer to $R_{3}$ than to $\mathrm{R}_{1} ; \mathrm{R}_{3}$ distinctly closer to $\mathrm{R}_{4+5}$ than to $\mathrm{R}_{2}$; $\mathrm{R}_{4}$ and $\mathrm{R}_{5}$ long stalked; $\mathrm{M}_{1}$ and $\mathrm{M}_{2}$ obviously separated at base; $\mathrm{CuA}_{2}$ arising from $3 / 4$ of cell; $\mathrm{CuP}$ degenerative, only distinct on tornus. Hindwing with Sc almost straight; Rs and $\mathrm{M}_{1}$ long-stalked; $\mathrm{M}_{2}$ slightly bent downwards; $\mathrm{CuA}_{2}$ arising from $4 / 5$ of cell.

Male genitalia (Fig. 1d): Uncus gradually narrowing toward distal, apex rounded. Valva ovate, ventral margin distally with a large dent, dorsal margin convex; sacculus narrow and short, with weakly sclerotized free termination, like a hook. Transtilla band-like, broad, weakly sclerotized, convex medially. Juxta inverted pentagonal-like. Aedeagus pointed apically, with small coecum penis; caulis rudimentary; vesica without cornuti.

Female. Unknown.

Distribution. China (Guizhou).

Host plant. Unknown.

Etymology. The new specific name is derived from the Latin word dentatus = dentate, in reference to the dent in the ventral margin of valva.

Acknowledgements. We thank Mr. K. R. Tuck of the Natural History Museum, London, for checking the specimens and providing valuable suggestions. We are also grateful to Dr. M. Horak of the Division of Entomology, CSIRO, Canberra, and Dr. Mei Ling Chan of the National Museum of Natural Science, Taipei, for providing us with helpful references, and to Prof. Zizhong Li of the Institute of Entomology, Guizhou University, Guiyang, for assisting us in the field. The research was supported by the National Nature Science Foundation of China for the Special Program.

\section{References}

Horak, M. 1984: Assessment of taxonomically significant structures in Tortricinae (Lep., Tortricidae). - Mitteilungen der Schweizerischen Entomologischen Gesellschaft 57: 3-64.

Kawabe, A. 1982: Tortricidae. — In: Inoue, H. et al. (eds.), Moths of Japan. Parts 1-2. Kodansha Co. Ltd., Tokyo. $966+552 \mathrm{pp}$.

Kuznetsov, V. I. 2001: Tortricidae (Olethreutidae, Cochylidae). - In: Ler, P. A. (ed.), Key to the insects of Russian Far East. Vol. V. Pt. 3, Trichoptera and Lepidoptera. Dal'nauka, Vladivostok. 622 pp.

Liu, Y. Q. \& Li, G. W. 2002: Fauna Sinica, Insecta, Vol. 27 , Lepidoptera, Tortricidae. - Science Press, Beijing. $463 \mathrm{pp}$.

Obraztsov, N. S. 1967: Notes on the genus Homonopsis V. Kuznetsov (Lepidoptera: Tortricidae). — Entomologische Berichten 27: 173-175.

Razowski, J. 1987: The Genera of Tortricidae (Lepidoptera). Part II: Palaearctic Childanotinae and Tortricinae. - Acta zoological cracoviensia 30(11): 141355.

Yasuda, T. 1972: The Tortricinae and Sparganothinae of Japan (Lepidoptera: Tortricidae) (Part I). — Bulletin of University of Osaka Prefecture, Ser. B, 24: 53-153.

Yasuda, T. 1975: The Tortricinae and Sparganothinae of Japan (Lepidoptera: Tortricidae) (Part II). — Bulletin of University of Osaka Prefecture, Ser. B 27: 80-251. 